\title{
INFLEXIONES DISCURSIVAS EN LA POESÍA DE ANTONIO GAMONEDA*
}

Tomás ALBALADEJO

Universidad Autónoma de Madrid

\section{1}

La poesía, como praxis artística del lenguaje y de la imaginación, en la que son activados y sometidos a la máxima tensión los dispositivos poiéticos de ésta y de aquél, se configura y se nos ofrece como una construcción dinámica y como un proceso de significado en los que están implicadas diversas funciones del lenguaje y en los que se relacionan proyectivamente de manera recíproca las categorías participantes en el hecho poético: poeta, poema y lector.

La poiesis y la interpretación están entrelazadas en la poesía, como lo están en la literatura en general, siempre que el autor crea un texto con el que intenta conseguir la implicación del lector. La poiesis desemboca en el espacio textual que es objeto poiético y también objeto hermenéutico y la actividad interpretativa es la contribución de quien lee el poema a la poiesis como resultado de la creación que en su actividad de lector le llega, pero también es la aportación de posibles poiesis alternativas en la reconstrucción semasiológica de la actividad onomasiológica. De este modo, la poesía no es algo distinto de la poiesis, no sólo por razones etimológicas, sino también por la necesaria proyección de cada una de las categorías antes mencionadas en las demás. En correspondencia, poética y hermenéutica se complementan y se relacionan proyectivamente sobre el objeto en el que confluyen y que constituye el eje alrededor del cual giran la creación y la interpretación. Ello sin olvidar la dimensión interpretativa de la creación ni la dimensión creadora de la interpretación: el poeta interpreta el mundo, la realidad, la imaginación y la poesía en un proceso que está vinculado a su creación y el lector interpretativamente crea propuestas de sentido con el fin de recrear la obra. Antonio García Berrio ha explicitado aspectos centrales de la lectura lírica:

La lectura del poema lírico implica un conjunto peculiar de operaciones de identificación con el multifacético mensaje del texto del poema. Parto, como puede constatarse, de la iniciativa de la identificación lectora como fundamento necesario del acto comunicativo de la lectura poética. Sin esa tensión hacia el

\footnotetext{
* Es resultado de la investigación realizada en el proyecto de I+D+I de referencia FFI2010-15160, concedido por el Ministerio de Ciencia e Innovación.
} 
encuentro en el espacio codificado de las intenciones del autor, no puede hablarse con exactitud de lectura propiamente dicha. ${ }^{1}$

En toda poesía hay retórica, como la hay en toda creación literaria, en toda expresión linguiística y en toda acción comunicativa del ser humano. Por supuesto, no entiendo ni utilizo el término «retórica» en el sentido negativo que, afortunadamente, cada vez va siendo menos frecuente, de «palabras sin contenido» o «palabras con poco contenido». Precisamente la retórica busca una adecuación entre expresión y contenido, entre eficacia comunicativa y uso de los recursos del lenguaje; de ahí el convencimiento de la necesidad de defender la utilización del término «retórica» en un sentido totalmente positivo. Al margen de cualquier significado negativo, toda poesía puede ser calificada de retórica, lo cual no quiere decir que en toda poesía se consiga un uso eficaz, en el mejor sentido retórico, de los dispositivos lingüístico-comunicativos que el poeta tiene a su disposición o puede obtener para lograr en el mayor grado posible la adecuación entre la expresión y el contenido y entre el conjunto semiótico formado por éste y aquélla y su voluntad poiética en la producción del poema.

La poesía de Antonio Gamoneda es una poesía en la que la retórica ocupa un importante lugar, para, lejos de apoyar la construcción de expresiones que no correspondan a un sentido o que carezcan de éste, contribuir a que cada uno de sus poemas posea la eficacia de la adecuación (gracias al aptum retórico ${ }^{2}$ ) entre expresión y sentido y alcance el resultado poético de trasmitir al lector, y de hacer que éste haga suya, la representación literaria que así construye y consigue el poeta ${ }^{3}$.

Del objeto de representación poética de Gamoneda forma parte la imperfección del mundo y la rotura del ser humano, a la que no es ajena la pertenencia de éste al mundo. Así, son muestra y prueba de esta rotura sintagmas como «esta memoria despedazada» $\mathrm{y}$ «esta pena arterial», que encontramos en este poema de Arden las pérdidas:

\author{
DE LAS violentas humedades, de \\ los lugares donde se entrecruzan \\ residuos de tormentas y sollozos, \\ viene \\ esta pena arterial, esta memoria \\ despedazada.
}

Aún enloquecen

\footnotetext{
${ }^{1}$ Antonio García Berrio, «La lectura lírica», en Antonio García Berrio, El centro en lo múltiple (Selección de ensayos), III. El contenido de las formas (1985-2005), ed. y estudio introductorio de Enrique Baena, Barcelona, Anthropos, 2009, pp. 58-67, p. 60.

${ }^{2}$ Heinrich Lausberg, Manual de Retórica literaria, trad. española de José Pérez Riesco, Madrid, Gredos, 1966-1967-1968, 3 vols., § 258.

${ }^{3}$ Sobre la representación véase Hannah Fenichel Pitkin, El concepto de representación, trad. española de Ricardo Montoro Romero, Madrid, Centro de Estudios Constitucionales, 1985.
} 
aquellas madres en mis venas. ${ }^{4}$

La estructura de cada uno de estos dos sintagmas ofrece un asiento poiético sobre el que se sitúan claves de su poesía: en «esta memoria despedazada» es el adjetivo que es el participio «despedazada» el que conduce el sustantivo «memoria» hacia la rotura y el que consolida el conjunto del sintagma en la poiesis de la representación de la rotura; en «esta pena arterial» es el sustantivo «pena» el que impulsa la modulación del adjetivo «arterial» e impide que éste quede desvinculado de la rotura. Si en «esta memoria desplazada», el adjetivo instala el sintagma en una posición semántica de activa representación de la rotura, en «esta pena arterial» sucede a la inversa, siendo el sustantivo el que atrae hacia dicha posición el adjetivo y, por tanto, el conjunto formado por sustantivo y adjetivo. El resultado es una representación entrecruzada de la rotura en una peculiar estructura morfosemántica que, sin constituir la figura de quiasmo, pertenece al amplio campo de lo quiástico, de tal modo que en ambos sintagmas ni el sustantivo ni el adjetivo quedan libres de la carga semántica de rotura, la cual es reforzada por la implicación de uno y otro en una recíproca impregnación en la que prevalece esta carga, dotando de pleno sentido al entrecruzamiento que se da en el conjunto de los dos sintagmas, en el que no hay que olvidar la doble presencia del adjetivo demostrativo «esta», por sus implicaciones en la referencialidad de la proximidad de la memoria y la pena al yo poemático. La presencia léxica del entrecruzamiento y la existencia de entrecruzamiento en la estructuración poemática son manifestación del principio de aptum, tan importante en el discurso retórico, en la poesía y en la literatura en general. No deja de contribuir a la representación de la ruptura el encabalgamiento por el que cada uno de los dos elementos del sintagma «esta memoria despedazada» está en un verso diferente. Al servicio de la ruptura está «la constelación de líneas que desbloquea la sintaxis» 5 . De este modo, las posibilidades constructivas morfológicas y semánticas, con intervención sintáctica, son empleadas poiéticamente con la mayor eficacia retórica para intensificar el significado del poema y para contribuir a trazar y afianzar el necesario eje poiético-hermenéutico que todo poema ha de tener para conectar al poeta con el lector y al lector con el poeta sobre un significado que constantemente está siendo construido.

La poesía es estímulo y también es respuesta, con su acto de poiesis Antonio Gamoneda responde a un mundo roto, de «sombras torturadas» -en el poema cuyo primer verso es «Hasta los signos vienen ${ }^{6}-$ que se acercan a los signos y contribuyen a intensificar su significado. La respuesta de la poiesis es de creación de significado porque el poeta cree necesario representar el mundo como él lo comprende, es de creación de significado de un mundo quebrado y divergente, con roturas causada por rupturas, por medio de una voz poética atravesada por la conciencia, a la vez, del mundo, del yo, de la propia voz, del poema. En el mundo roto está el dolor humano, cuya representación lleva a cabo el

\footnotetext{
${ }^{4}$ Antonio Gamoneda, Arden las pérdidas, en Antonio Gamoneda, Esta luz. Poesía reunida (1947-2004), epílogo de Miguel Casado, Barcelona, Galaxia Gutenberg, 2004, p. 435.

${ }^{5}$ Antonio Méndez Rubio, «Espacio de lo increíble. Palabras en torno a la poética de Antonio Gamoneda», en Martín Muelas Herráiz y Ángel Luis Luján Atienza (coords.), Antonio Gamoneda. Leer y entender la poesía, Cuenca, Ediciones de la Universidad de Castilla-La Mancha, 2010, pp. 33-42, p. 36.

${ }^{6}$ Antonio Gamoneda, Arden las pérdidas, op. cit., p. 436.
} 
poeta $^{7}$. Y es que, aunque esta conciencia de sí mismo y de lo objetivable y lo objetivado desde el sujeto es imprescindible para la existencia de la poesía, en el caso del mundo roto al que no deja de acercarse la memoria despedazada, se hace más intensa, de modo que consiga superar la rotura y el despedazamiento con el fin de poder dar poiéticamente cuenta de ellos y, hechos poema, transferirlos al lector.

2. Pero la representación literaria no es solamente de un referente extraído del mundo o construido por la imaginación, sino que también lo es de la visión y la comprensión del mundo que tiene el autor y de su conciencia y para representarlas puede servirse también de determinados dispositivos de construcción lingüístico-artística que las manifiesten y plasmen en la obra literaria. De este modo, en la poesía de Antonio Gamoneda tienen, en aras de la capacidad poética de dar cuenta del mundo, de representarlo en sus contradicciones y en sus entrecruzamientos -como el de «residuos de tormentas y sollozos» en el poema antes citado, y la pena arterial y la memoria despedazada vienen de donde se produce este entrecruzamiento-, una función determinante en la construcción del poema las inflexiones discursivas. En el discurso poemático que se ha iniciado en una dirección de sentido, compleja como es propio de la poesía, pero constituyendo un desarrollo semántico y pragmático con la creación de un espacio que tiende a la estabilidad textual en la construcción sintáctica y en el establecimiento semántico, la inflexión constituye una ruptura de las líneas del discurso que se pueden proyectar desde el espacio discursivo ya trazado. Se trata de una ruptura en el lenguaje del poema y en los presupuestos y las expectativas de carácter semántico y pragmático que pueden establecerse en el conjunto del poema, en el que lo que existe y lo que puede ser previsto se sitúan en una relación dialéctica con la que el poeta crea el espacio del poema, que no solamente está formado por el lenguaje con el que lo compone, sino también por lo que está fuera de los límites de la construcción linguiística del poema, por lo que, sin ser poema, lo delimita y, por tanto, también lo construye, lo hace poema. La inflexión del discurso del poema es, además de ruptura de dichas líneas, ruptura y rotura del significado y despedazamiento de la conciencia de éste como parte del poema y del mundo, es rotura con la que el poeta busca establecer una correspondencia con el mundo, con la realidad y con lo imaginado, que también es mundo. La inflexión discursiva del poema es, así, una rotura del discurso que construye la comprensión del mundo y, por tanto, contribuye a construir el poema. La inflexión rompe para construir, para reforzar la conciencia del lector ante el poema, una vez que ha sido producida precisamente por la intensidad de la conciencia del poeta. Así, la intensión ${ }^{8}$ del poema en la obra de Gamoneda no es solamente resultado de la transformación de la extensión, de la representación lingüística e intensional de la extensión, sino que es producto también de una intensionalización ${ }^{9}$ que

\footnotetext{
7 «Este proceso - escribe Francisco Vicente Gómez- configura un sujeto poético que se resiste a silenciar lo visto y lo vivido porque aún arde en él la pérdida humana», Francisco Vicente Gómez, «Habitar la palabra. Poiesis y razón ética en Antonio Gamoneda», en Barcarola, 70, 2007, pp. 306-314, p. 308.

${ }^{8}$ Sobre intensión y extensión véase Rudolf Carnap, The Logical Syntax of Language, ed. by C. K. Ogden, trad. inglesa de Amethe Smeaton, Londres, Routledge and Kegan Paul, 1971, reimpr., pp. 245 y ss.

${ }^{9}$ Sobre el concepto de intensionalización véase Tomás Albaladejo, Semántica de la narración: la ficción realista, Madrid, Taurus, 1992, pp. 27 y ss.
} 
puede ser considerada extraextensional y que permite la obtención de una intensión poemática en la que se representan actitudes ante el mundo por medio de elementos lingüísticos de discordancia; ello, por supuesto, junto a la intensionalización consistente en la transformación de la extensión ${ }^{10}$.

La inflexión discursiva está presente de diversas formas en la poesía de Gamoneda. Me ocupo a continuación de algunas de estas formas.

2. 1. En primer lugar me centraré en la inflexión discursiva conseguida por medio de la sustentatio. Desempeña una extraordinaria y compleja función poemática en la poesía de Gamoneda la sustentatio, que es suspensión, expectación; es un dispositivo retórico que consiste en un giro semántico y pragmático basado en el mantenimiento, en el sostenimiento de la atención, y que se resuelve con una expresión no esperada. Esta figura de pensamiento frente al público fue planteada en la Institutio oratoria por Quintiliano, que hace referencia al nombre dado por Celso:

Sed non numquam communicantes aliquid inexpectatum subiungimus, quod et per se schema est, ut in Verrem Cicero: 'quid deinde? quid censetis? furtum fortasse aut praedam aliquam?' deinde, cum diu suspendisset iudicum animos, subiecit quod multo esset improbius. Hoc Celsus sustentationem uocat. ${ }^{11}$

Esta figura consiste en el planteamiento de una línea de desarrollo discursivo de un discurso retórico o de un texto literario con una inflexión de carácter semántico y pragmático por la que dicha línea es quebrada, un giro discursivo lleva a romper la expectación sustentada por el desarrollo anterior. David Pujante ha prestado temprana y cuidadosa atención a esta figura ${ }^{12}$.

Como figura que es de pensamiento frente al público, en la sustentatio es decisivo su funcionamiento pragmático, pero, como todo elemento pragmático, tiene una fundamentación en lo semántico y en lo textual, ya que, si no fuera por el giro en el contenido, plasmado textualmente, no se produciría el giro pragmático en el ámbito comunicativo del discurso retórico o del texto literario; es combinación de una creación de expectativas comunicativas y de la ruptura de éstas. Esta figura tiene una gran importancia no sólo en la comunicación retórica, sino también en la literatura, por la vinculación que produce entre el lector y el texto cuyo desarrollo interpretativo lleva a cabo, con el vuelco de su atención en el giro discursivo. Entre los poemas en los que se da esta figura se puede citar «Navacerrada, abril», de Seguro azar de Pedro Salinas, y entre las obras narrativas con sustentatio quiero destacar el relato Nyū Yōku tankō no higeki (La tragedia de la mina de carbón de Nueva York) del autor japonés Haruki Murakami, por la brusca inflexión discursiva de carácter narrativo que hay en su final.

En la poesía de Antonio Gamoneda, esta figura de pensamiento ante el público es planteada en una combinación de figuras, lo cual complica, y sin duda enriquece, el texto poemático. Por un lado,

\footnotetext{
${ }^{10} \mathrm{Al}$ ocuparse de Descripción de la mentira, Jiménez Heffernan escribe: «Así las palabras de Gamoneda: proclamación proferida. Pero insisto: su tensión es interna. Es intensión. Es inscritura», Julián Jiménez Heffernan, «De líquenes inevitables. Un glosario para Antonio Gamoneda», apud Antonio Gamoneda, Descripción de la mentira, $2^{\mathrm{a}}$ ed., Madrid, Abada, 2006, p. 71.

${ }^{11}$ Quintiliano, Institutio oratoria, ed. de Michael Winterbottom, Oxford, Oxford University Press, 1970, 2 vols., 9. 2. 22.

12 David Pujante, El hijo de la persuasión. Quintiliano y el estatuto retórico, $2^{\mathrm{a}}$ ed. corregida y aumentada, Logroño, Instituto de Estudios Riojanos, 1999, p. 223; David Pujante, Manual de Retórica, Madrid, Castalia, 2003, pp. $259,268$.
} 
la sustentatio es combinada con la exclamatio ${ }^{13}$, la exclamación, y, por otro, con la interrogatio ${ }^{14}$, la interrogación retórica. Puesto que esta interrogación no requiere una respuesta, su función es en muchas ocasiones próxima a la exclamación, si bien la diferencia de ésta en todo momento su condición de pregunta. En la poesía, la interrogación retórica se hace interrogación poética, pero no deja de ser retórica, por lo que se la puede denominar «interrogación retórico-poética». Tanto en una combinación como en otra, la inflexión configurada por la sustentatio se encuentra al final del poema, constituyendo el cierre del poema precisamente el giro de carácter semántico y pragmático que abre un espacio lingüístico-poiético interpretativamente inesperado para el lector.

En la poesía de Antonio Gamoneda se encuentran varios casos de sustentatio con exclamación, como se analizará a continuación. Así, en el poema cuyo primer verso comienza con «Esta hora no existe, esta ciudad no existe», de Libro del frío, tras explorar el tiempo y el espacio y también la memoria, en una expresión de la referencia de lo que no existe o no se ve, pero está en el tiempo vivido que es recordado, el poeta termina el poema con una exclamación introducida por «ah», la cual supone una inflexión semántico-pragmática en relación con el desarrollo precedente del texto poemático, que forma el que podemos llamar espacio expectante:

ESTA hora no existe, esta ciudad no existe, yo no veo estos álamos, su geometría en el rocío.

Sin embargo, éstos son los álamos extinguidos, vértigo de mi infancia.

Ah jardines, ah números. ${ }^{15}$

El verso final del poema, bajo la forma de exclamación, contiene la inflexión, el giro, estando constituida la sustentatio por el conjunto expresivo formado por los versos anteriores y por este verso, por lo que es una figura de proyección textual y está expandida por el conjunto del poema, estando compuesta por un planteamiento previo que se resuelve con la exclamación que da fin al poema.

Pero la sustentatio puede estar construida de tal modo que en el desarrollo precedente a la inflexión haya elementos que puedan servir de anuncio de ésta. Es lo que sucede en el poema de Pedro Salinas antes mencionado, «Navacerrada, abril», en el que hay un indicio de la inflexión final en la expresión «arranque eléctrico», si bien solamente cuando se leen los tres últimos versos se interpreta dicha expresión como un sutil anuncio o anticipo del final ${ }^{16}$. La inflexión puede, por tanto, producirse

\footnotetext{
${ }^{13}$ Heinrich Lausberg, Manual de Retórica literaria, cit., $\$ 809$.

${ }^{14}$ En la amplia bibliografía sobre la interrogación retórica, véase Heinrich Lausberg, Manual de Retórica literaria, cit., $\$ \S$ 766-779; Klaus Schöpsdau, «Frage, rhetorische», en Gert Ueding (Hrsg.), Historisches Wörterbuch der Rhetorik, Tubinga, Max Niemayer, 1996, vol. III, pp. 445-454; Paul de Man, Alegorías de la lectura. Lenguaje figurado en Rousseau, Nietzsche, Rilke y Proust, trad. española de Enrique Lynch, Barcelona, Lumen, 1990; Carlos Piera, Contrariedades del sujeto, Madrid, Visor, 1993, pp. 65-77; Marc Dominicy, «La pregunta poética», en Cuadernos Hispanoamericanos, 643, 2004, pp. 15-22.

${ }^{15}$ Antonio Gamoneda, Libro del frío, en Antonio Gamoneda, Esta luz. Poesía reunida (1947-2004), op. cit., p. 341.

16 Recordemos este poema de Seguro azar, en Pedro Salinas, Poesías completas, prólogo de Jorge Guillén, $2^{\text {a }}$ ed., Barcelona, Barral, 1975, p. 116:
}

Los dos solos, ¡Qué bien aquí, en el puerto, altos! Vencido verde, triunfo de los dos, al venir 
contando con algún elemento lingüístico presente previamente en el poema; en uno de los poemas de Lápidas, el que comienza con el verso cuyas primeras palabras son «En la oquedad de Dios», el verso final, en el que se encuentra la inflexión, está formado por una exclamación cuya primera parte («Ah paloma final») ha sido anticipada parcialmente en el primer verso del poema con la expresión, también exclamativa, «ah paloma viviente». En los casos en los que la inflexión es parcialmente anticipada no deja de haber sustentatio, pues siempre aparecen en la inflexión elementos nuevos, como en el final del poema de Pedro Salinas o como sucede con el adjetivo «final» junto a «Ah paloma» y «va a ser noviembre» en el último verso del poema de Antonio Gamoneda al que me estoy refiriendo:

EN LA oquedad de Dios, ah paloma viviente, te obligué a la lectura del silencio. Y fulgías.

Tú eres temporal en dos abismos,

azul entre dos muertes, entre dos lenguas físicas.

Ah paloma final, va a ser noviembre. ${ }^{17}$

La oposición entre «paloma viviente» y «paloma final» sirve, a pesar de la limitación a la identificación total que suponen los dos diferentes adjetivos, de anticipo de una parte de la inflexión del último verso, en la que, junto al adjetivo «final» es decisiva la expresión temporal de la inmediatez de uno de los dos meses del año plenamente otoñales. El desarrollo poemático va desde vacíos espaciotemporales como la oquedad, el silencio, los abismos, hasta el tiempo concreto representado por el mes de noviembre, plasmación de la temporalidad atisbada en los abismos.

Que la sustentatio se resuelva con exclamación implica, por lo general, que haya una presencia de vocativo en los sintagmas con los que se produce la inflexión. Hay de este modo una llamada a la instancia lectora, aunque ésta no forme parte del sintagma exclamativo; esta llamada permite al lector advertir, en el espacio poemático del enunciado, al destinatario de la exclamación. Es necesario

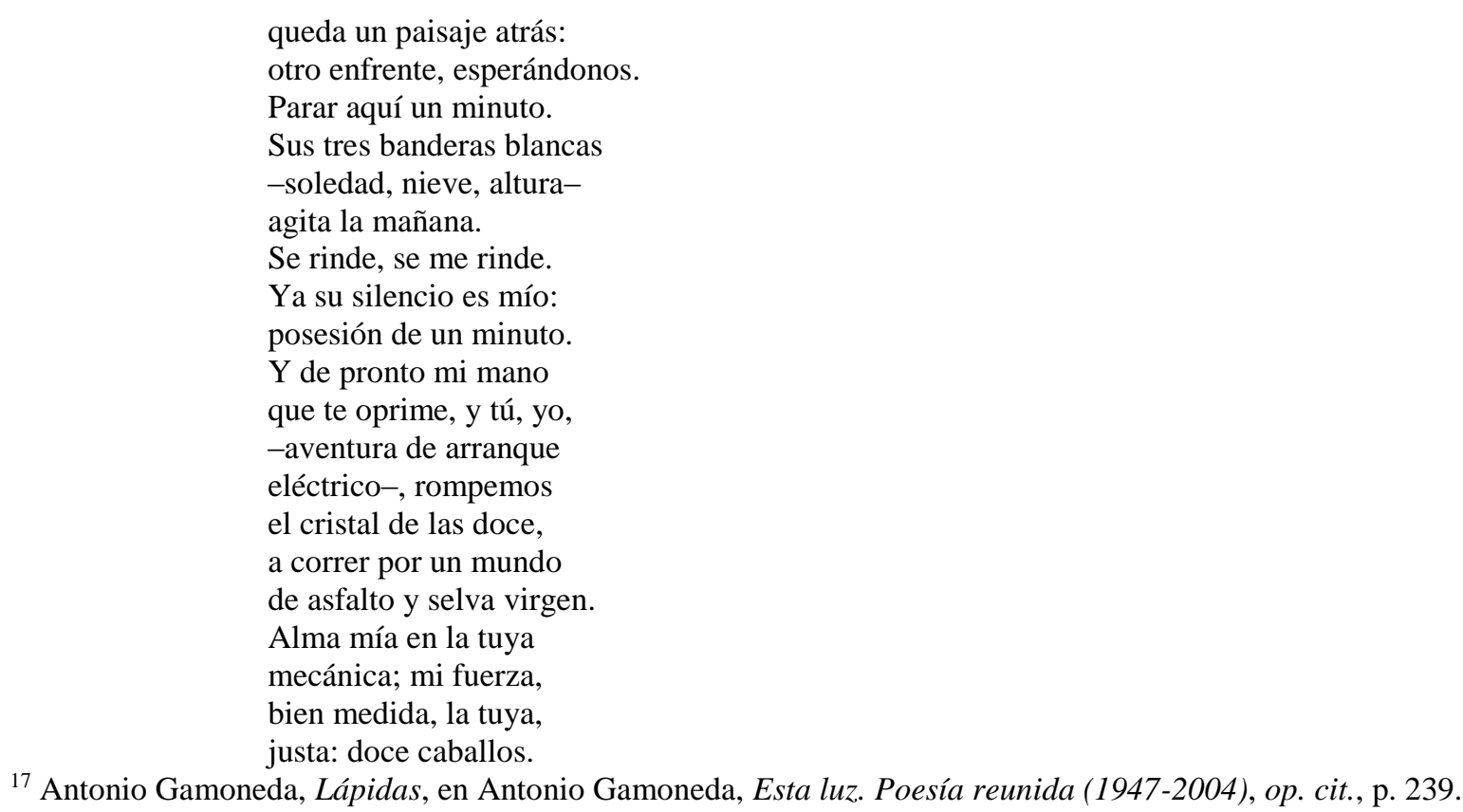

${ }^{17}$ Antonio Gamoneda, Lápidas, en Antonio Gamoneda, Esta luz. Poesía reunida (1947-2004), op. cit., p. 239. 
destacar las implicaciones pragmáticas de la inflexión en el caso de que el enunciado del poema contenga formas verbales en segunda persona del plural y vocativo en plural. Es lo que sucede en el poema de Lápidas que comienza con «Asediados por ángeles y ceniza cárdena»:

ASEDIADOS por ángeles y ceniza cárdena enmudecéis hasta advertir la inexistencia

y el viento entra en vuestro espíritu.

Respiráis el desprecio, la ebriedad del hinojo bajo la lluvia: blancos en la demencia como los ojos de los asnos en el instante de la muerte,

ah desconocidos semejantes a mi corazón. ${ }^{18}$

En este poema, la inflexión contribuye a que el lector establezca una relación de acercamiento con la exclamación, por las posibilidades pragmáticas que abre a una identificación del destinatario del enunciado y el de la enunciación.

Otra forma que adopta la sustentatio en la poesía de Antonio Gamoneda es la construida con interrogación retórico-poética, interrogación que es retórica por su constitución y por su funcionamiento discursivo y que es poética por su alojamiento activo en el arte de lenguaje -literario y retórico- y por su presencia en el poema como texto, en el texto concreto del poema por su imbricación en el tejido poemático destilado en la poiesis, y en la poesía como género literario. La fuerza de la interrogación retórico-poética es muy intensa en toda clase de textos; en el discurso retórico la pregunta constituye un recurso lingüístico-artístico por el que resultan implicados los oyentes en la elocutio y también en los demás niveles y componentes operacionales del discurso que está emitiendo el orador en su pronuntiatio; en la poesía, contribuye a abrir en el espacio pragmático y hermenéutico la interpretación por la expansión semántica que este recurso supone al ser planteada una cuestión y no ofrecerse respuesta, bien se deje ésta abierta, bien se dé por supuesta. La interrogación, como dispositivo del arte de lenguaje, está plenamente situada en el espacio de la interdiscursividad, de las relaciones entre discursos, entre clases de discursos y entre las disciplinas que se ocupan del estudio de los discursos ${ }^{19}$.

En la poesía de Antonio Gamoneda se encuentran muchos casos de esta forma de sustentatio, con la inflexión producida por una pregunta con la que se cierra el poema, a la vez que permanece abierto como corresponde a la interrogatio por la apertura comunicativa que toda pregunta sin responder supone. En Descripción de la mentira hay varias interrogaciones retórico-poéticas en los versos finales de los distintos poemas o secciones poemáticas de esta obra si la consideramos como un solo poema ${ }^{20}$.

\footnotetext{
${ }^{18}$ Antonio Gamoneda, Lápidas, op. cit., p. 231.

${ }^{19}$ Tomás Albaladejo, «Retórica, comunicación, interdiscursividad», en Revista de Investigación Lingüística, 8, 2005 , pp. 7-33.

${ }^{20}$ Como escribe Miguel Casado, «Descripción de la mentira es un solo texto poético, compuesto por fragmentos de variable tamaño - de una sola línea, de dos páginas...- que van separados por pausas, también de duración diversa, representada en la diversa medida de los espacios en blanco contenidos en la página», Miguel Casado, El curso de la edad. Lecturas de Antonio Gamoneda (1987-2007), Madrid, Abada, 2009, p. 46, véase también p. 186; asimismo Miguel Casado, «Cifras arden en los ojos: Historia de una mirada», en Un Ángel Más, 2, 1987, pp. 155-162.
} 
Destacaré, por su interés y paralelismo dentro de la obra, la de la sección poemática de varias páginas que comienza con «Las hortensias extendidas en otro tiempo», en la que el verso final es la interrogación que cito a continuación junto con el verso que la precede:

Las hortensias extendidas en otro tiempo decoran la estancia más arriba de mi cuerpo.

¿Qué lugar es éste, qué lugar es éste? ¿Cómo estás aún en mi corazón? ${ }^{21}$

Esta doble interrogación retórico-poética tras un desarrollo discursivo en relación con el cual supone un giro, intensificado por la repetición de la primera de las dos preguntas que la componen, al centrarse en la propia situación y presencia, es parte de la sustentatio con la que se da la inflexión en esta sección poemática de Descripción de la mentira, sin duda una de las obras más complejas de Gamoneda, con una interacción parte-todo y todo-parte en la que se sitúa en gran medida la construcción arquitectónica de la obra. Si bien hay en este poema otras interrogaciones retóricopoéticas en el interior del texto que no producen la inflexión que es parte de la sustentatio, la de los versos antes citados, como otras muchas de la poesía de Gamoneda, contribuye extraordinariamente a la intensionalización extraextensional con una construcción lingüístico-artística que supone un cuestionamiento, desde el propio lenguaje y desde el propio discurso, del desarrollo discursivo. Es decisivo el papel de las inflexiones discursivas para esta intensionalización extraextensional, que se une a la intensionalización de la extensión en la obtención de un poema en el que la complejidad de su construcción representa la complejidad de lo representado. La discordancia, el aturdimiento y la tensión están tanto en lo representado como en la representación ${ }^{22}$. Discordancia que, paradójicamente, es construida en la complejidad de la poesía de Gamoneda gracias al principio retórico del aptum, de la concordancia entre la construcción y lo representado.

En el verso final de la última sección poemática de Descripción de la mentira, el primer verso de la cual comienza así: «El olvido es mi patria vigilada», se encuentra una interrogación retóricopoética, como parte de la sustentatio. Tras un desarrollo anterior en el que el poeta comienza tejiendo una red isotópica de representación del vacío, con palabras como «olvido», «desconocido», «silencio», «desaparición», para continuar con la red isotópica de representación de la ausencia de correspondencia, con expresiones como «traición», «creaste la mentira», «relato incomprensible», «profundidad de la mentira», redes isotópicas que van alimentando la sustentatio previamente a su parte resolutiva en la que ejerce su función la inflexión, y tras un penúltimo verso que representa lo efímero, basado léxicamente en «instante» y en «alarido entre cristales», está la interrogación retórico-

\footnotetext{
${ }^{21}$ Antonio Gamoneda, Descripción de la mentira, en Antonio Gamoneda, Esta luz. Poesía reunida (1947-2004), op. cit., p. 200.

${ }^{22}$ Escribe Prieto de Paula: «Tras un prolongado silencio, Descripción de la mentira (1977) supuso un ensayo de poesía épica. La plétora versicular del libro verbalizaba el aturdimiento del poeta, contundido por oleadas sucesivas de recuerdos que venían a parar a un presente que era resultado de una mentira histórica colectiva y una derrota personal»; Ángel Luis Prieto de Paula, «Antonio Gamoneda y la construcción de un poeta», en Espacio / Espaço Escrito. Revista de Literatura en Dos Lenguas, 23-24 (Homenaje a Antonio Gamoneda y a António Ramos Rosa), 2004, pp. 99-104, p. 102. Y Jiménez Heffernan: «Gamoneda escribe líneas en tensión. Y lo que da tensión a las líneas (versos) es lo que se trata de averiguar. Una fuerza mendaz (tono, ritmo, prosodia, aliento, voz) que vertebra, angulariza, dispone, secuencia, pauta»; Julián Jiménez Heffernan, «De líquenes inevitables. Un glosario para Antonio Gamoneda», cit., pp. 99-100.
} 
poética de doble composición. Reproduzco los dos últimos versos de esta última sección del macropoema que es Descripción de la mentira, los dos últimos versos de esta obra:

Y ese alarido entre cristales, esas heridas que no son visibles más que en el instante del amor...

¿Qué hora es ésta, qué yerba crece en nuestra juventud? ${ }^{23}$

Las últimas preguntas instaladas en versos finales de sección poemática a las que me he referido - ¿Qué lugar es éste, qué lugar es éste? ¿Cómo estás aún en mi corazón?» y «QQué hora es ésta, qué yerba crece en nuestra juventud?»- se complementan en la búsqueda de lo temporal y de lo espacial por la voz poética y por la conciencia por dicha voz manifestada, en el enunciado y en la enunciación.

Las de las dos secciones poemáticas de Descripción de la mentira de las que me he ocupado son inflexiones que interrogan sobre el lugar en el que se está y sobre la hora en la que se vive, con la función de los pronombres demostrativos como deixis temporal en «¿Qué hora es ésta»y como deixis espacial $^{24}$ en «¿Qué lugar es éste». Estas preguntas se presentan unidas a otras preguntas en los mismos versos, respectivamente: «qué yerba crece en nuestra juventud?» y «¿Cómo estás aún en mi corazón?», preguntas que son realmente las últimas, al estar cada una de ellas en la segunda parte de los versos, y que intensifican la apertura semántica que constituyen las preguntas que las preceden en cada verso. La interrogación sobre el tiempo y sobre el espacio es aquí una doble búsqueda de la orientación y la razón que quizás puedan contribuir para el propio sujeto del poema a la explicación y a la comprensión de lo expresado en el discurso anterior de estas secciones poemáticas de Descripción de la mentira, pero también son una doble manifestación de la desesperación por el desconocimiento de las propias coordenadas espacio-temporales. Al no haber respuesta a estas interrogaciones retórico-poéticas, lo que queda es la propia irracionalidad vinculada al desconocimiento del tiempo y el espacio que se quiere identificar, a pesar de las configuraciones deícticas respecto del tiempo y del espacio -«hora... ésta», «lugar... éste»-, que revelan una conciencia del sujeto, una conciencia del yo poético, que es consciente de estar en un hic et nunc y de la autorreferencialidad de este aquí y este ahora y que se proyecta hacia la posibilidad de una concreción en sus dos componentes de espacio y tiempo. Esta proyección es expresada en la inflexión con las interrogaciones, pues a la conciencia del aquí y del ahora, en la que se ha desarrollado el discurso, le falta la concreción, la identificación, que se reclama en los mencionados últimos versos. Se da una oposición entre el espacio y el tiempo autorreferenciales y las vías abiertas por la interrogación respecto del espacio y del tiempo. El espacio del poema es

\footnotetext{
${ }^{23}$ Antonio Gamoneda, Descripción de la mentira, op. cit., p. 222.

${ }^{24}$ Sobre la deixis en la poesía de Antonio Gamoneda, véase el excelente trabajo de investigación de Diploma de Estudios Avanzados de Carlota Fernández-Jáuregui Rojas, La experiencia del lenguaje: Movimientos y paradojas referenciales en la obra poética de Antonio Gamoneda, defendido el 10 de marzo de 2008 en la Universidad Autónoma de Madrid; asimismo su tesis doctoral: Carlota Fernández-Jáuregui Rojas, Poesía y deixis: hacia una poética gestual en la obra de César Vallejo y de Antonio Gamoneda, defendida el 27 de febrero de 2012 en la Universidad Autónoma de Madrid. Véase también Carlota Fernández-Jáuregui Rojas, «Apuntes para una poética del índice en César Vallejo y Antonio Gamoneda», en Despalabro. Revista de Humanidades, 1, 2007, pp. 61-73, especialmente a propósito de la sustitución de «la fuerza deíctica del lenguaje por la fuerza autodeíctica del lenguaje poético», p. 62.
} 
espacio presentado («dargelstellte Raum») ${ }^{25}$. Las deixis espacio-temporales por medio de los pronombres demostrativos que hay en los citados versos finales de sección poemática sostienen una oposición: por un lado son representación de la conciencia intensa del momento y del espacio concreto, pero por otro lado su situación en las preguntas desvela el desconocimiento de qué momento y qué espacio se trata, desconocimiento en el que la desesperación encuentra anclaje. Mientras que los deícticos ejercen una fuerza centrípeta, de concentración en sí mismos, en un aquí y en un ahora, y en la propia conciencia del sujeto, su situación en sendas preguntas retóricas, en interrogaciones retóricopoéticas, alienta una fuerza centrífuga, por la que los deícticos son proyectados a un espacio y a un tiempo que son abiertos por ser desconocidos. La conciencia del hic et nunc crea un centro, mientras que el desconocimiento de cuáles sean concretamente, más allá de su relatividad deíctica, el aquí y el ahora, es una múltiple vía de proyección espacio-temporal que queda abierta con las preguntas.

Del desconocimiento surgen las interrogaciones retórico-poéticas en el final de los dos poemas, en las que el poeta proclama no sólo su necesidad del conocimiento de lugar y tiempo, sino también el desconocimiento de éstos y la imposibilidad o la dificultad de llegar a ese conocimiento.

La inflexión discursiva como sustentatio con interrogación retórico-poética no se limita en Gamoneda a Descripción de la mentira, está presente en otras obras del autor. Así en el poema cuyo primer verso comienza con «Entra en tu cuerpo y tu cansancio se llena de pétalos», de Libro del frío, que reproduzco completo:

\section{ENTRA en tu cuerpo y tu cansancio se llena de pétalos. Laten en ti bestias felices: música al borde del abismo.}

Es la agonía y la serenidad. Aún sientes como un perfume la existencia.

Este placer sin esperanza, ¿qué significa finalmente en ti?

¿Es que va a cesar también la música?26

En este poema hay dos interrogaciones retórico-poéticas, ambas con la característica propia de este dispositivo de fundamentación retórica, pues no buscan realmente una respuesta. Pero de estas dos interrogaciones, solamente la segunda de ellas, la que forma el verso final del poema, constituye inflexión discursiva por sustentatio. El verso final, si bien contiene la palabra «música», presente en el primer verso, es inflexión sobre todo gracias a su configuración como interrogación que hace que

\footnotetext{
${ }^{25}$ No deja de estar plenamente vigente la reflexión de Ingarden sobre el espacio presentado como espacio propio de la obra literaria: «Handelt es sich in einem literarischen Werke um dargestellte Gegenstände, die ihrem Gehalte nach "real" sind, und soll ihr Realitätstypus bewahrt werden, so müssen sie als zeitliche und als sich im Raume befindende, evtl. auch als selbst räumliche, dargestellt werden. Der Raum aber, der hierbei in Frage kommt, ist nicht der r e a le , einzige Weltraum und auch nicht der "Orientierungsraum", welcher zu der wahrnehmungsmäßigen originären Gegebenheit von Dingen notwendig gehört, eine konstitutive Unterstufe der Erscheinung des einzigen realen Raumes bildet und als solcher in sich selbst eine Daseinsrelativität auf das wahrnehmende Subjekt aufweist. Andererseits ist es auch nicht der i d e a 1 e homogene, geometrische Raum, die reine drei-dimensionale Punktmannigfaltigkeit. Endlich ist es auch nicht der "Vorstellungsraum", der wesensmäßig zu jedem anschaulichen V o r s t e 11 e n von ausgedehnten Gegenständen gehört und mit dem realen Raum nie zur Deckung und zur Einheit gebracht werden kann. Sondern es ist ein -wenn man so sagen darf- eigener Raum, der zu der dargestellten "realen” Welt wesensmäßig gehört», Roman Ingarden, Das literarische Kunstwerk, Vierte, unveränderte Auflage, Tubinga, Max Niemeyer, 1972, p. 235.

${ }^{26}$ Antonio Gamoneda, Libro del frío, op. cit., p. 404.
} 
este último verso se plantee como una forma de rebeldía frente a la realidad, de desesperada llamada, anunciada en el desarrollo discursivo anterior del poema.

Las interrogaciones retórico-poéticas son uno de los elementos poemáticos que más intensamente favorecen que el poema sea una construcción lingüística e imaginaria compartida por el poeta y por el lector y que funcione como necesario e insustituible espacio de confluencia poiéticohermenéutica entre ambos. Las interrogaciones retóricas son elaboradas con la voluntad, por parte del orador y de los demás productores de discursos de distintas clases, de que sean compartidas con los receptores. El hecho de preguntar, con el consiguiente cambio de entonación, implica en el discurso retórico una apelación a la conciencia de los oyentes, que, en su interpretación del discurso, hacen suyas las interrogationes del orador. Un proceso de implicación comunicativa semejante se produce en la poesía con las interrogaciones retórico-poéticas, que son, tanto por su construcción morfosintáctica y semántica como por su configuración suprasegmental, por su entonación, una llamada al lector con intención de hacer que comparta las preguntas, que se introduzca en ellas interpretativamente, que indague en su origen y en sus motivaciones y que se sitúe en el abierto campo de las respuestas o de la no respuesta, en una especie de solidaridad comunicativa con el poeta. Las interrogaciones retórico-poéticas tienen, de este modo, una extraordinaria fuerza estética -en sus distintos sentidos, tanto en el relativo a la percepción como en el de la belleza artística- que permite que la praxis poiética contribuya a que el lector, en su interpretación, construya y haga suyos los impulsos de duda, desesperación, desorientación, perplejidad, etc. del poeta en su proyección en el poema. La fuerza poiética genera así una fuerza estética y la conjunción de ambas está en la base del gran poema, del poema que, más allá de la literariedad, alcanza la poeticidad como valor ${ }^{27}$.

La sustentatio con interrogación retórico-poética es un dispositivo que en la obra de Antonio Gamoneda dinamiza con plena intensidad la relación que en el poema se establece entre el poeta y el lector y que hace que el espacio poemático trascienda los límites de la construcción lingüística del texto del poema en una expansión por la conciencia del poeta y por la conciencia del lector, del mismo modo que para Aristóteles el discurso retórico (lógos) abarca al orador y al oyente, que forman parte de él ${ }^{28}$.

En la poesía de Gamoneda también hay, aunque no es frecuente, inflexión por sustentatio sin exclamación y sin interrogación. En el poema de Lápidas cuya primera sección es una extensa expresión versicular que comienza con «Los jueves por la tarde se cerraba la escuela...», la segunda y última sección poemática es inflexión en relación con el espacio discursivo expectante anterior. Así termina el poema: «Pasaban trenes en la tarde y su tristeza permanece en mí» ${ }^{29}$.

\footnotetext{
${ }^{27}$ Sobre la poeticidad véase Antonio García Berrio, «Lingüística, literaridad / poeticidad (Gramática, Pragmática, Texto)», en 1616. Anuario de la Sociedad Española de Literatura General y Comparada, II, 1979, pp. 125-170; Antonio García Berrio, «Qué es lo que la poesía es», en Antonio García Berrio, El centro en lo múltiple (Selección de ensayos), III. El contenido de las formas (1985-2005), cit., pp. 46-57.

${ }^{28}$ Aristóteles, Retórica, ed. del texto con aparato crítico, traducción, prólogo y notas de Antonio Tovar, Madrid, Instituto de Estudios Políticos, 1971, 1358a38-1358b8: «Porque consta de tres cosas el discurso: el que habla, sobre lo que habla y a quién; y el fin se refiere a éste, es decir, al oyente».

${ }_{29}$ Antonio Gamoneda, Lápidas, op. cit., p. 256.
} 
2. 2. La inflexión discursiva en la obra de Antonio Gamoneda se da también con una forma específica de encabalgamiento $^{30}$, el que voy a llamar encabalgamiento anatrópico, consistente en la separación de una oración en dos versos, quedando un elemento breve de la oración en el verso encabalgante y el resto de la oración en el verso encabalgado; el elemento breve que es separado está situado tras una pausa sintáctica, habitualmente marcada con punto y seguido o con punto y coma. Como todo encabalgamiento, consiste en la subordinación de la estructura morfosintáctica y semántica a la sintaxis propia del poema, en el cual la unidad constructiva es el verso con su organización rítmica $^{31}$. Este encabalgamiento, que tiene una importante presencia en la poesía de Gamoneda, se presenta asociado al conflicto entre la sintaxis lingüística y la sintaxis versal. Si bien todo encabalgamiento es semántico y pragmático, además de sintáctico, su peso es decisivo para el significado de los dos versos en él implicados, el verso encabalgante y el verso encabalgado, y su incidencia pragmática es importante en la actividad interpretativa del lector, que encuentra un significado partido y ha de recomponerlo sin dejar de sustraerse a los efectos de la sintaxis del verso, propios de la poesía.

Aron Kibédi Varga, al ocuparse de los efectos de discordancia en el poema, se refiere, siguiendo a Jean Mazaleyrat, al encabalgamiento («enjambement»), al «surjet»y al «rejet», como tres procedimientos diferenciados ${ }^{32}$. Como expresa Kibédi Varga, que también sigue a Jules Marouzeau ${ }^{33}$, a diferencia de los otros dos procedimientos, el encabalgamiento no produce siempre un efecto especial $^{34}$. El «surjet», también llamado «contre-rejet» es, en palabras de Mazaleyrat:

\footnotetext{
30 A propósito del encabalgamiento, véase, dentro de una extensa bibliografía, Antonio Quilis, Estructura del encabalgamiento en la métrica española (Contribución a su estudio experimental), Madrid, Consejo Superior de Investigaciones Científicas, 1964; José Domínguez Caparrós, Métrica española, Madrid, Síntesis, 1993, pp. 105-111; Esteban Torre, Métrica española comparada, Sevilla, Universidad de Sevilla, 2000, pp. 67 y ss.; Aron Kibédi Varga, Les constantes du poème. Analyse du langage poétique, París, Picard, 1977, pp. 103 y ss. Sobre verso libre, versículos y encabalgamiento, véase Samuel Gili Gaya, Estudios sobre el ritmo, ed. de Isabel Paraíso, Madrid, Istmo, 1993, p. 93-95. Tiene gran interés el planteamiento de Dámaso Alonso del encabalgamiento abrupto y el encabalgamiento suave; Dámaso Alonso, Poesía española. Ensayo de métodos y límites estilísticos, $5^{\text {a }}$ ed., $3^{\text {a }}$ reimpr., Madrid, Gredos, 1981, pp. 68 y ss.

${ }^{31}$ En este sentido, son de total actualidad los planteamientos del formalismo ruso, especialmente de Tynjanov. Véase Antonio García Berrio, Significado actual del formalismo ruso, Barcelona, Planeta, 1973, pp. 161 y ss.

${ }^{32}$ Aron Kibédi Varga, Les constantes du poème. Analyse du langage poétique, cit., pp. 103 y ss. Kibédi Varga cita la tesis doctoral de Jean Mazareylat, Le rhythme de l'alexandrin moderne, son évolution de Victor Hugo aux poètes contemporains, le problème de la discordance (thèse soutenue en Sorbonne le 20 novembre 1954, manuscrit) y las notas multicopiadas de un curso: Jean Mazareylat, Notions de versification (Notes prises au cours de M. Mazaleyrat) (U.N.E.F.-F.G.E.L., Groupe d'étude de lettres modernes, Centre de polycopie de la F.G.E.L., s.l.n.d.) y ofrece esta definición de «surjet» de Mazareylat: «un élément de faible étendue, qui, placé à la fin d'un vers ou d'un hemistiche, se rattache étroitement par la construction à l'hemistiche ou au vers suivant et prend de par sa position une valeur particulière», cit. por Aron Kibédi Varga, Les constantes du poème. Analyse du langage poétique, cit., p. 103. Posteriormente, Mazareylat utilizará «contre-rejet» en lugar de «surjet»; Jean Mazaleyrat, Éléments de métrique française, París, Armand Colin, 1990, p. 123.

33 Jules Marouzeau, Lexique de la terminologie linguistique. Français - Allemand - Anglais - Italien, $3^{\mathrm{e}}$ ed. augmentée et mise à jour, $3^{\mathrm{e}}$ tirage, París, Librairie Orientaliste Paul Geuthner, 1969.

${ }^{34}$ Aron Kibédi Varga, Les constantes du poème. Analyse du langage poétique, cit., p. 103-104.
} 
Un procédé rhythmique selon le quel un élément verbal bref, placé à la fin d'un vers ou d'un hémistiche, se trouve étroitement lié par la construction au vers ou à l'hémistiche suivant et prend de par sa position une valeur particulière. ${ }^{35}$

El «rejet» es la construcción inversa: en éste el elemento separado está al comienzo del verso encabalgado $^{36}$. En mi opinión, tanto el «surjet»como el «rejet», al consistir en desmembramientos oracionales en los que un elemento de extensión reducida queda en un verso anterior o en un verso posterior, respectivamente, en relación con el verso con el que está estrechamente relacionado, pueden ser considerados formas de encabalgamiento, ya que son dos fenómenos en los que se cumple el principio del encabalgamiento, consistente que la oración va más allá de los límites del verso ${ }^{37}$; el que tanto en el «surjet» como en el «rejet» resulte destacado un elemento linguiístico no implica necesariamente que haya que separar estos fenómenos del encabalgamiento, del que también, junto a éstos, forma parte el fenómeno habitualmente considerado encabalgamiento, en el que no es resaltado un elemento lingüístico. Isabel Paraíso, que ha estudiado el fenómeno con gran acierto, denomina contra-encabalgamiento abrupto al «contre-rejet»:

Dentro del amplio tema del encabalgamiento, vamos a tratar de un caso especial: el que en métrica francesa se conoce como «contre-rejet», y que nosotros denominaremos contra-encabalgamiento abrupto. Consiste en que un fragmento versal breve -inferior a la mitad del verso- está aislado por pausa interna en posición final de verso, y enlaza con el verso siguiente. ${ }^{38}$

Morier distingue entre «contre-enjambement»-para él equivalente a «surjet» ${ }^{39}-\mathrm{y}$ «contrerejet»; emplea «contre-enjambement» para los casos en los en los que la ruptura se produce entre $\operatorname{versos}^{40}$ y reserva «contre-rejet» para los casos en los que la ruptura es entre hemistiquios ${ }^{41}$.

El que denomino encabalgamiento anatrópico es un «surjet», un contra-encabalgamiento abrupto, pues en él un elemento lingüístico breve, formado por una o por muy pocas palabras, situado en un verso determinado forma parte de la oración que en su mayor parte se encuentra en el verso siguiente; se diferencia, pues, del encabalgamiento en el que hay equilibrio entre el verso encabalgante y el verso encabalgado. Con el adjetivo «anatrópico» quiero hacer referencia al movimiento hacia arriba, hacia atrás, que es necesario hacer para reconstruir el sentido completo de la oración situada en dos versos, confirmándolo, reafirmándolo -y por tanto para alcanzar también el sentido pleno de los

\footnotetext{
35 Jean Mazaleyrat, Éléments de métrique française, cit., p. 123 (la cursiva es del texto citado); véase también Aron Kibédi Varga, Les constantes du poème. Analyse du langage poétique, cit., p. 103.

${ }^{36} \mathrm{El}$ «rejet», también según Mazaleyrat, es «un procédé rhythmique selon lequel un élément verbal bref, placé au début d'un vers ou d'un hémistiche, se trouve étroitement lié par la construction au vers ou à l'hémistiche précédent et prend de par sa position une valeur particulière», Jean Mazaleyrat, Éléments de métrique française, cit., p. 119 (la cursiva es del texto citado); véase también Aron Kibédi Varga, Les constantes du poème. Analyse du langage poétique, cit., p. 103-104 y Jules Marouzeau, Lexique de la terminologie linguistique. Français - Allemand - Anglais - Italien, cit., p. 198-199. Morier llama «contre-enjambement» al «surjet»; Henri Morier, Dictionnaire de Poétique et de Rhétorique, París, Presses Universitaires de France, $3^{\mathrm{e}}$ édition augmentée et entièrement refondue, 1981, pp. 303 y ss.

${ }^{37}$ Antonio Quilis, Estructura del encabalgamiento en la métrica española (Contribución a su estudio experimental), cit., pp. 79 y ss.

${ }^{38}$ Isabel Paraíso, La métrica española en su contexto románico, Madrid, Arco/Libros, 2000, pp. 105-106.

${ }^{39}$ Henri Morier, Dictionnaire de Poétique et de Rhétorique, cit., p. 1051.

${ }^{40}$ Henri Morier, Dictionnaire de Poétique et de Rhétorique, cit., pp. 303 y ss.

${ }^{41}$ Henri Morier, Dictionnaire de Poétique et de Rhétorique, cit., pp. 308 y ss.
} 
versos y del poema-, debiéndose recuperar para este sentido el elemento lingüístico situado en el verso anterior, es decir, el elemento lingüístico destacado en el verso encabalgante, elemento que es muy importante para el significado poemático.

La inflexión discursiva por encabalgamiento anatrópico se produce por el choque entre el verso (que normalmente es el verso final, aunque hay casos en los que se produce en versos distintos de los finales) y el elemento lingüístico que por el encabalgamiento está separado del verso final, de acuerdo con la sintaxis versal, aunque por sentido completa el verso final y forma con él una unidad de significado que es quebrada por el encabalgamiento. Este elemento lingüístico no forma parte del verso encabalgado que tiene la posición de verso final, sino del verso anterior, el verso encabalgante, siendo el último elemento lingüístico del poema que, en la linealidad del significante, se encuentra inmediatamente antes del verso final. Tras el elemento lingüístico separado por el encabalgamiento se abre, a causa de la sintaxis versal, un abismo de significado ${ }^{42}$, un vacío interpretativo que inmediatamente es ocupado por el significado del último verso. Para este significado es clave dicho elemento, que funciona como modificador o como centrador del significado parcial de la oración (el correspondiente a la parte de ésta que hay en el verso encabalgado), que sería distinto si el poema careciera de dicho elemento, que, alojado en el verso anterior, hace posible una inflexión en contra de la linealidad, una inflexión hacia atrás, retardada por la comprensión total del último verso, la cual no es posible sin dicho elemento. Es muy importante la condición retórica del encabalgamiento, de acuerdo con Paul Fussell:

The sudden shortening of a line must say something. The degree of line-integrity or enjambment must refract the rhetorical status of the poem's address. And any momentary deviation into meter must validate itself, must appear not a lapse but a significant bold stroke. For the reader to attend to things like these may be harder than for him to respond to, say, a skillfully reversed foot in a metered line. But he must learn to attend to them if he is to take a pleasure less doctrinal than artistic in the poetry of his own time. ${ }^{43}$

A la complejidad de este encabalgamiento hay que añadir que la lectura del poema no es siempre completamente lineal, como tampoco lo es siempre su escritura. Puesto que el elemento lingüístico separado conduce a un súbito abismo en el que queda en suspenso el poema, el verso encabalgado se encuentra en condiciones de producir un primer impulso de significado en ausencia del elemento separado, y éste es inmediatamente recuperado con su consiguiente actuación sobre el significado del último verso, ya en un segundo impulso de significado, contemplador del último verso y del imprescindible elemento lingüístico separado por el encabalgamiento.

Esta inflexión discursiva es fruto, en un primer momento, de la ruptura entre el fragmento oracional más extenso y un elemento breve, que puede ser un modificador adverbial o una forma verbal necesaria para la representación poemática de la situación del sujeto. En un segundo momento, la inflexión se completa con la recuperación del elemento separado, que hace que el verso encabalgado,

\footnotetext{
${ }^{42}$ A propósito del abismo en la poesía de Antonio Gamoneda, Juan José Lanz escribe: «La escritura de Gamoneda es una escritura abismal, responde a una "poética del abismo" ante el que se sitúa el lenguaje a cada momento», Juan José Lanz, «Arden las pérdidas y el aprendizaje del olvido», en José María Castrillón y Jordi Doce (monográfico coordinado por), Antonio Gamoneda. En la lógica moral, Ínsula, 736, 2008, pp. 15-17, p. 15.

${ }^{43}$ Paul Fussell, Poetic Meter and Poetic Form, revised ed., Nueva York, Random House, 1979, p. 89.
} 
como último verso del poema, resulte centrado semántica y pragmáticamente tanto en el resultado dinámico del proceso creativo como en una praxis interpretativa de reconstrucción de la poiesis. Todo ello frente al desarrollo discursivo anterior del poema.

Es conveniente, en aras de la explicación de esta inflexión, prestar atención a los versículos o versos largos de la poesía de Antonio Gamoneda, que, como los de Leaves of Grass de Walt Whitman, producen un efecto de proximidad comunicativa al romper, al menos parcialmente, las barreras entre el verso y la prosa y al conducir la construcción oracional a una construcción versal no sujeta a límites. Uno de los rasgos de la poesía de Gamoneda es la tendencia a la adecuación entre la sintaxis rítmica del verso y la sintaxis lingüística, de lo que son prueba los numerosos versos largos que se encuentran en su obra. La inflexión por encabalgamiento anatrópico es facilitada por la existencia de estos versículos en la poesía de Gamoneda y por su función de acercamiento lingüístico en el conjunto del discurso poemático, aunque en muchos casos este encabalgamiento se produce sin que lo precedan versos largos ${ }^{44}$. Así, en el poema cuyo primer verso comienza así: «Oyes la destrucción de la madera», de Libro del frío, el verso encabalgante es un verso largo, cuya última palabra, «Vas», es el elemento lingüístico perteneciente a la oración cuya mayor parte se encuentra en el verso encabalgado, el último del poema:

OYES la destrucción de la madera (los termes ciegos en sus venas), ves las agujas y los armarios llenos de sombra.

Es la siesta mortal. ¡Cuánta niñez bajo los párpados!

Como el tábano triste en el verano, apartas de tu rostro la sarga negra de tu madre. Vas

a despertar en el olvido. ${ }^{45}$

Además de ser semántica, esta inflexión es pragmática por el choque que producen en el receptor la partición del significado y la inseparable fusión que tienen lugar por la recuperación del elemento separado, que en este poema es un elemento tan importante como la forma verbal «Vas». Se trata de una inflexión compleja que puede descomponerse en su funcionamiento en un proceso de dispersión y en un proceso de concentración. Y, en su conjunto, esta inflexión supone quebrar el discurso

\footnotetext{
${ }^{44}$ Para Miguel Casado, estos versos tienen una función en el poema que se puede considerar arquitectónica; refiriéndose a Descripción de la mentira explica su posición en los espacios intermedios del poema, escribe: «No se trata exactamente de "ritmo de ideas", sino del ritmo conseguido al disponer esos contenidos en cada unidad de sentido, por la relación recíproca entre los miembros del período, etc. Aparte del ya citado empleo de la reiteración, Gamoneda provoca esas tensiones y distensiones mediante tres procedimientos principales: la extensión de los versículos, la estructura sintáctica y la alternancia del lenguaje sentencioso con el figurado.

Los tres mecanismos funcionan de modo integrado, resultando, por ejemplo y sin que se trate de una norma general, que los versículos más breves compuestos por oraciones simples y por afirmaciones sentenciosas vayan situados al principio, en el centro y al final de los fragmentos; también es esa la posición más frecuente de las reiteraciones, paralelismos y estribillos más notorios. Los espacios intermedios, en cambio, suelen ir ocupados por versículos más extensos, de mayor complicación sintáctica y lenguaje cargado de imágenes. Así, en este sistema de oleaje, los primeros son el eje articulador del discurso, soportes de la mayor densidad conceptual; los segundos son como ampliaciones suyas, de tono más emotivo o evocador», Miguel Casado, El curso de la edad. Lecturas de Antonio Gamoneda (1987-2007), cit., pp. $48-49$.

${ }^{45}$ Antonio Gamoneda, Libro del frío, op. cit., p. 391.
} 
poemático precedente, adquiriendo también el carácter de inflexión versal, cuando supone un contraste con los versos precedentes al ser éstos largos.

En el poema de Cecilia cuyo primer verso es «Huyó de mí» hay una inflexión por encabalgamiento anatrópico en la que el verso encabalgante no es verso largo, aunque sí lo es el verso que le precede:

Huyó de mí.

Quizá está en ti y apenas lo sientes en tu pequeño corazón.

Sí; es una sombra; no

pesa en tu corazón. ${ }^{46}$

La presencia del adverbio «no» en el penúltimo verso supone una ruptura oracional por la separación de este elemento lingüístico respecto del resto de la oración, que está formado por el último verso. Dicha presencia es la clave de esta inflexión producida por el encabalgamiento anatrópico que, con plena intención estética, descoyunta la oración en favor de la construcción versal, dejando fuera del último verso un elemento clave para el significado como es la negación, lo cual produce la que podemos considerar una sacudida o una conmoción interpretativa en el lector, una violenta ruptura semántica por el contraste entre el significado de la oración final sin la negación y su significado con la negación, con la consiguiente rotura poemática. Por otro lado, el adverbio «no», que ocupa en el penúltimo verso una posición simétrica en relación con el adverbio «Sí», ejerce una fuerza de contrapeso en el significado de este verso, si bien finalmente, una vez superada la ruptura producida por la organización versal e incorporado al significado de la última oración, lo que hace es contribuir semánticamente al papel central del lexema «sombra» del verso encabalgante ${ }^{47}$.

En el libro de poemas Canción errónea puede observarse el encabalgamiento anatrópico con el adverbio «no» en el verso encabalgante. Así en el poema cuyo primer verso es «Juan, acércate: quiero»:

estaba solo el corazón: la cólera

envejecía en el hígado. ${ }^{48}$

\footnotetext{
${ }^{46}$ Antonio Gamoneda, Cecilia, en Antonio Gamoneda, Esta luz. Poesía reunida (1947-2004), op. cit., p. 507.

${ }^{47}$ La sombra es importante en la obra de Gamoneda, Un armario lleno de sombra es el título de sus memorias de infancia -hay que recordar aquí los versos antes citados: «OYES la destrucción de la madera (los termes ciegos en sus venas), ves las agujas / y los armarios llenos de sombra»-, en las que la persistencia de la sombra y su proyección desde el pasado tienen una función clave: «En el olvido están los recuerdos. Advierto que mi aprendizaje de vejez no es otra cosa que la forma que adoptan ahora en mí el pasado y sus sombras», Antonio Gamoneda, Un armario lleno de sombra, Barcelona, Galaxia Gutenberg, 2009, p. 5; «la luz eléctrica había hecho que los objetos perdieran su valor de apariciones pero el armario seguía lleno de sombra», Antonio Gamoneda, Un armario lleno de sombra, cit., p. 12.

${ }^{48}$ Antonio Gamoneda, Cecilia, en Antonio Gamoneda, Esta luz. Poesía reunida (1947-2004), op. cit., p. 507.
} 
En el poema de Arden las pérdidas que comienza con «En los desvanes habitados por palomas», la inflexión por encabalgamiento anatrópico es planteada por la separación del elemento lingüístico «Estoy» del resto de la oración de la que forma parte, resto que es el último verso:

\begin{abstract}
EN LOS desvanes habitados por palomas cuyas alas tiemblan entre tinieblas y cristales veo la pureza de rostros que se forman en la lluvia y

lágrimas sobre úlceras amarillas.
\end{abstract}

Son los desvanes de la infancia. Estoy

atravesando olvido. ${ }^{49}$

El encabalgamiento anatrópico se produce en este poema al estar el elemento lingüístico «Estoy» en el penúltimo verso y formar parte de una oración cuyo resto, «atravesando olvido» es el último verso. Dicho elemento lingüístico separado del resto de la oración es clave para el significado de ésta, al ser su núcleo verbal y aportar, como forma verbal de primera persona del presente de indicativo, informaciones tan importantes como la del sujeto del enunciado, la del tiempo, la del modo. Frente al desarrollo anterior del discurso del poema, este encabalgamiento supone una ruptura que es semántica y pragmática, que concierne al significado y a su recomposición y al choque que produce en el lector. La sorpresa de éste por la separación versal de un elemento lingüístico imprescindible para el sentido del último verso y para el poema como totalidad discursiva y la recuperación interpretativa de dicho elemento constituyen unos movimientos interpretativos que representan una inflexión respecto de la construcción discursiva precedente y de la actitud interpretativa del lector.

Son muchos los ejemplos de la inflexión por encabalgamiento anatrópico que pueden encontrarse en la poesía de Antonio Gamoneda. En algunos casos, la función del elemento lingüístico separado del resto de la oración que está en el último verso es una aportación semántica cuya presencia en dicha oración, sin carecer de importancia, no tiene tantas implicaciones en el significado como en los dos poemas a los que acabo de referirme; sucede así en el poema cuyo primer verso comienza con «Huyen heridas por el amanecer», de Libro del frío, en el que el elemento lingüístico que queda en el penúltimo verso, separado del último («sólo hay invierno en las ramas inmóviles»), es el adverbio «Ya», importante para el significado de la oración y del poema entero, pero con un peso semántico diferente del que tienen «no» $\mathrm{o}$ «Estoy» ${ }^{50}$. Un caso similar es el del poema cuyo comienzo es «La infección es

\footnotetext{
${ }^{49}$ Antonio Gamoneda, Canción errónea, Barcelona, Tusquets, 2012, p. 59.

${ }^{50}$ Antonio Gamoneda, Libro del frío, op. cit., p. 388. El texto completo del poema es: HUYEN heridas por el amanecer, laten sobre las aguas y su blancura se abre en ti: avefrías.

Viajan de lo visible a lo invisible. Ya sólo hay invierno en las ramas inmóviles.
} 
más grande que la tristeza», también de Libro del frío, en el que el elemento lingüístico que permanece en el penúltimo verso es «luego», siendo éste el último verso: «las desapariciones bajan al corazón» ${ }^{51}$.

Conviene prestar atención a los poemas en los que el verso cuyo final ocupa el elemento lingüístico separado del grueso de la oración, que está en el verso siguiente, es un verso partido ${ }^{52}$. Sirva como ejemplo el poema cuyo primer verso es «Gritan ante los muros calcinados», de Arden las pérdidas:

GRITAN ante los muros calcinados.

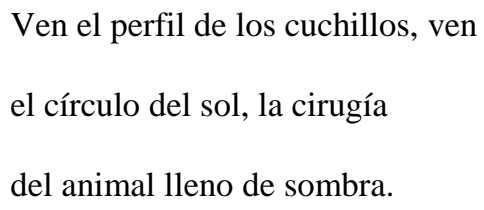

Silban

en las fístulas blancas..$^{53}$

En este poema la inflexión producida por el encabalgamiento anatrópico se ve reforzada por el aislamiento del elemento lingüístico separado en el verso anterior, «Silban».

Esta inflexión se produce en algunos poemas de Gamoneda no solamente por encabalgamiento que afecta al penúltimo y al último verso, sino también a versos anteriores, lo cual aumenta la intensidad poética del dispositivo. Es el caso del poema cuyo primer verso comienza con «Como la cólera en el hígado», de Libro del frío, en el que hay dos encabalgamientos anatrópicos sucesivos:

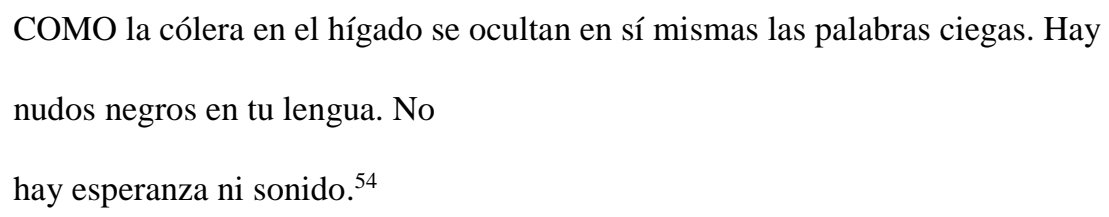

En el primero de los dos encabalgamientos, el elemento lingüístico «Hay» queda separado del resto de la oración de la que forma parte, que no ocupa totalmente el segundo verso, ya que en éste se encuentra el elemento lingüístico «No», perteneciente a la oración que continúa en el tercer y último verso del poema. La inflexión es doble en este poema y afecta a la totalidad de sus tres versos, produciéndose los movimientos interpretativos en los dos encabalgamientos. Si normalmente este encabalgamiento funciona como inflexión y como retroinflexión, este funcionamiento resulta potenciado por la existencia de doble encabalgamiento, lo cual da al poema un ritmo semántico e interpretativo que multiplica el efecto pragmático de los tres versos que lo componen: en el lector persiste el eco próximo de su lectura del primer verso, que es verso encabalgante respecto del segundo,

\footnotetext{
${ }^{51}$ Antonio Gamoneda, Libro del frío, op. cit., p. 373.

${ }^{52}$ Elena Varela Merino, Pablo Moíño Sánchez y Pablo Jauralde Pou, Manual de Métrica Española, Madrid, Castalia, 2005, pp. 59 y ss.

${ }_{53}$ Antonio Gamoneda, Arden las pérdidas, op. cit., p. 439.

${ }^{54}$ Antonio Gamoneda, Libro del frío, op. cit., p. 385.
} 
el cual es verso encabalgado en relación con el primero, pero, a su vez, es verso encabalgante, siendo el último su verso encabalgado correspondiente. El encadenamiento de los encabalgamientos en un poema muy breve deja solamente como espacio discursivo no inflexivo, de llegada a la inflexión, de tensa progresión lineal de la construcción lingüística del poema, la primera parte del primer verso, es decir, todo él excepto «Hay». La combinación de los dos encabalgamientos en este poema hace que posea la inflexión discursiva a partir de un punto muy próximo al comienzo y que ésta se extienda por una gran espacio del poema, en términos relativos, a diferencia de los anteriores poemas en los que he examinado el encabalgamiento anatrópico, pues en ellos éste se encuentra al final tras el desarrollo discursivo previo del poema.

La inflexión por encabalgamiento anatrópico es un dispositivo clave en muchos de los poemas de Antonio Gamoneda. El planteamiento y la explicación ofrecidos por Fernando Lázaro Carreter a propósito de la poética del arte mayor castellano pueden ayudarnos a explicar la función literaria de este encabalgamiento y su papel en su praxis poética ${ }^{55}$. Si en el verso de arte mayor castellano los cambios acentuales producen una inestabilidad constructiva, en los poemas de Gamoneda en los que se da este encabalgamiento hay una inestabilidad generadora de poeticidad, por el ahormamiento versal de las oraciones y de las relaciones internas de éstas, no siendo ajena a la relación con los versos precedentes, que de otra manera también poseen poeticidad, producida por la proximidad prosódica a la lengua comunicativa.

Esto nos lleva a una reflexión sobre el hecho de que incluso planteamientos poiéticos diferentes y a veces opuestos generan poeticidad en el poema como espacio compartido cuya constitución es tan compleja que en ella caben distintas estrategias de creación de lenguaje que conviven en el poema como totalidad y en la que llamo «la lengua del poema» y aun «la lengua de cada poema», una especie de idiolecto poemático por el que son absorbidas y hechas propias desde las expresiones más extrañas hasta las más cotidianas, desde las construcciones más alejadas del uso normal de la lengua hasta las más próximas a éste. Unas y otras son incorporadas a dicha lengua en un proceso de poiesis del propio lenguaje, con una impregnación recíproca que contribuye a situarlas en el espacio comunicativo del poema y de la proyección semiótica de éste en un impulso de transformación del habla en lengua, de la realización discursiva en sistema o en parte del sistema. La creación del poema implica en Antonio Gamoneda la de la lengua del poema, de la que forman parte palabras y expresiones habituales en la lengua no literaria y palabras y expresiones alejadas de lo cotidiano ${ }^{56}$. Tanto unas como otras se incorporan plenamente a la lengua del poema y al poema y se combinan formando un conjunto, un

\footnotetext{
${ }^{55}$ Fernando Lázaro Carreter, «La Poética del Arte mayor castellano», en Fernando Lázaro Carreter, Estudios de Poética (La obra en sí), $2^{\mathrm{a}}$ ed., Madrid, Taurus, 1979, pp. 75-112, especialmente pp. 91-92.

${ }^{56}$ Véase Miguel Casado, El curso de la edad. Lecturas de Antonio Gamoneda (1987-2007), cit., pp. 49 y ss. «En el poema - escribe José Manuel Cuesta- las palabras esconden un secreto que las separa de su uso ordinario», José Manuel Cuesta Abad, «Pasar la lengua», en República de las Letras, 104, 2007, pp. 109-115, p. 113. Como Antonio Ortega afirma a propósito de Descripción de la mentira, «nada parece estar gastado por el grosero manoseo de lo cotidiano. Todo parece, en su distancia, rodeado de una luz de dignidad. Su palabra logra apartarnos del camino de la indiferencia y el hastío. Como si en el acto de limpiar un espejo todo se convirtiera en un rito fruto de la potencia verbal que se desata. Sólo la palabra, con toda su carga primigenia, nos devuelve su fuerza», Antonio Ortega, «La realidad plástica en Descripción de la mentira», en VV. AA., Antonio Gamoneda, Madrid, Calambur, 1993, pp. 109-117, p. 117.
} 
todo, que, como tal, es de carácter poético en su globalidad y en sus componentes. Como un rasgo de interdiscursividad, del mismo modo que en la construcción ficcional literaria los elementos ficcionales atraen hacia su estatuto a los no ficcionales por la ley de máximos semánticos ${ }^{57}$, en la poesía, en el poema y en la lengua del poema, los elementos que puedan ser considerados más poéticos atraen hacia su propio estatuto el resto de los elementos, constituyéndose el conjunto de todos ellos como una construcción plenamente poética. En este sentido, la combinación en algunos poemas de Gamoneda de versos en los que hay adecuación entre sintaxis lingüística y sintaxis versal y versos en los que hay encabalgamiento se resuelve en la existencia, en dichos poemas, de una construcción poemática que, como conjunto formado por ambos tipos de versos, posee globalmente, como tal conjunto, una sintaxis que es ajena a la habitual, aunque partes del mismo no lo sean, pero resultan atraídas hacia la caracterización general del conjunto por las partes más rupturistas respecto de la construcción propia de la sintaxis comunicativa.

3. Tanto en las inflexiones por sustentatio como en las inflexiones por encabalgamiento, funciona, desde la perspectiva poiética y desde la perspectiva hermenéutica, el contraste entre el espacio textual expectante y el que constituye propiamente la inflexión, que destaca precisamente sobre dicho espacio anterior en el desarrollo discursivo del poema.

Las inflexiones discursivas en la poesía de Antonio Gamoneda forman parte de un arte de lenguaje con el que se lleva a cabo una representación perfecta de un mundo imperfecto, en la que los fenómenos de la realidad y de los distintos submundos posibles alternativos y siempre complementarios de ésta, así como la negación de dichos fenómenos, aparecen poéticamente descoyuntados y en la que la temporalidad y la especialidad quedan desprendidas del fenómeno, pero no de la conciencia. Sin embargo, tanto el poeta como el lector, en lo que es uno de los logros de la poesía, reconducen -uno poiética y otro hermenéuticamente y, por consiguiente, construyendo también el poema en la interpretación-, ese mundo a lenguaje, a lenguaje poético, a representación literaria, y, en aquél y en ésta, a una manifestación de la fractura de la realidad en la configuración del poema. Esto es así porque el lector se adhiere con su construcción interpretativa a la propuesta del poeta y, consciente de ésta y de su propia interpretación, da los pasos que confirman su participación activa en el espacio poemático. Y todo ello con un lenguaje que plasma la fractura fracturándose en su plano de la expresión y en su plano del contenido y dirigiéndose, a pesar de todo, a la unidad del poema, que es reforzada por las tensiones internas y por su correspondencia con una realidad problemática.

\section{Referencias bibliográficas}

Albaladejo, Tomás, Semántica de la narración: la ficción realista, Madrid, Taurus, 1992.

AlbalADEJo, Tomás, «Retórica, comunicación, interdiscursividad», Revista de Investigación Lingüística, 8, 2005, 7-33.

${ }^{57}$ Sobre la ley de máximos semánticos véase Tomás Albaladejo, Semántica de la narración: la ficción realista, cit., pp. $52-63$. 
Alonso, Dámaso, Poesía española. Ensayo de métodos y límites estilísticos, $5^{\mathrm{a}}$ ed., $3^{\mathrm{a}}$ reimpr., Madrid, Gredos, 1981.

ARISTÓTELES, Retórica, ed. del texto con aparato crítico, traducción, prólogo y notas de Antonio Tovar, Madrid, Instituto de Estudios Políticos, 1971.

CARNAP, Rudolf, The Logical Syntax of Language, ed. by C. K. Ogden, trad. inglesa de Amethe Smeaton, Londres, Routledge and Kegan Paul, 1971, reimpr.

CASADO, Miguel, «Cifras arden en los ojos: Historia de una mirada», Un Ángel Más, 2, 1987, 155162.

CASADO, Miguel, El curso de la edad. Lecturas de Antonio Gamoneda (1987-2007), Madrid, Abada, 2009.

Cuesta ABAD, José Manuel, «Pasar la lengua», República de las Letras, 104, 2007, 109-115.

DE MAn, Paul, Alegorías de la lectura. Lenguaje figurado en Rousseau, Nietzsche, Rilke y Proust, trad. española de Enrique Lynch, Barcelona, Lumen, 1990.

Domínguez CAPARrós, José, Métrica española, Madrid, Síntesis, 1993, 105-111.

DominICY, Marc, «La pregunta poética», Cuadernos Hispanoamericanos, 643, 2004, 15-22.

FENICHEL PITKIN, Hannah, El concepto de representación, trad. española de Ricardo Montoro Romero, Madrid, Centro de Estudios Constitucionales, 1985.

FERNÁNDEZ-JÁUREGUI RoJAS, Carlota, «Apuntes para una poética del índice en César Vallejo y Antonio Gamoneda», Despalabro. Revista de Humanidades, 1, 2007, 61-73.

FERNÁNDEZ-JÁUREgUi RoJAS, Carlota, La experiencia del lenguaje: Movimientos y paradojas referenciales en la obra poética de Antonio Gamoneda, trabajo de investigación de Diploma de Estudios Avanzados, defendido el 10 de marzo de 2008 en la Universidad Autónoma de Madrid. FERnÁndeZ-JÁuRegui RojAs, Carlota, Poesía y deixis: hacia una poética gestual en la obra de César Vallejo y de Antonio Gamoneda, tesis doctoral defendida el 27 de febrero de 2012 en la Universidad Autónoma de Madrid.

Fussell, Paul, Poetic Meter and Poetic Form, revised ed., Nueva York, Random House, 1979.

GamonedA, Antonio, Esta luz. Poesía reunida (1947-2004), epílogo de Miguel Casado, Barcelona, Galaxia Gutenberg, 2004.

GAMONEDA, Antonio, Un armario lleno de sombra, Barcelona, Galaxia Gutenberg, 2009.

GAMONEDA, Antonio, Canción errónea, Barcelona, Tusquets, 2012.

GArcía Berrio, Antonio, Significado actual del formalismo ruso, Barcelona, Planeta, 1973.

GARCÍA BERrio, Antonio, «Lingüística, literaridad / poeticidad (Gramática, Pragmática, Texto)», 1616. Anuario de la Sociedad Española de Literatura General y Comparada, II, 1979, 125-170. GARCÍA BERRIO, Antonio, «Qué es lo que la poesía es», El centro en lo múltiple (Selección de ensayos), III. El contenido de las formas (1985-2005), ed. y estudio introductorio de Enrique Baena, Barcelona, Anthropos, 2009, 46-57.

GiLi GayA, Samuel, Estudios sobre el ritmo, ed. de Isabel Paraíso, Madrid, Istmo, 1993. 
GómEZ, Francisco Vicente, «Habitar la palabra. Poiesis y razón ética en Antonio Gamoneda», Barcarola, 70, 2007, 306-314.

IngARDEN, Roman, Das literarische Kunstwerk, Vierte, unveränderte Auflage, Tubinga, Max Niemeyer, 1972.

JIMÉNEZ HEFFERNAN, Julián, «De líquenes inevitables. Un glosario para Antonio Gamoneda», en Antonio Gamoneda, Descripción de la mentira, 2a ed., Madrid, Abada, 2006.

KiBedi VARGA, Aron, Les constantes du poème. Analyse du langage poétique, París, Picard, 1977.

LANZ, Juan José, «Arden las pérdidas y el aprendizaje del olvido», en José María Castrillón y Jordi Doce (monográfico coordinado por), Antonio Gamoneda. En la lógica moral, Ínsula, 736, 2008, $15-17$.

LÁZAro CARreter, Fernando, Estudios de Poética (La obra en sí), $2^{\mathrm{a}}$ ed., Madrid, Taurus, 1979.

LAUSBerg, Heinrich, Manual de Retórica literaria, trad. española de José Pérez Riesco, Madrid, Gredos, 1966-1967-1968, 3 vols.

MAZAREYLAT, Jean, Le rhythme de l'alexandrin moderne, son évolution de Victor Hugo aux poètes contemporains, le problème de la discordance, thèse soutenue en Sorbonne le 20 novembre 1954, manuscrit.

MAZAREYlat, Jean, Notions de versification. Notes prises au cours de M. Mazaleyrat, U.N.E.F.F.G.E.L., Groupe d'étude de lettres modernes, Centre de polycopie de la F.G.E.L., s.l.n.d.

MaZAlEyrat, Jean, Éléments de métrique française, París, Armand Colin, 1990.

MARouZEAU, Jules, Lexique de la terminologie linguistique. Français - Allemand-Anglais - Italien, $3^{\mathrm{e}}$ ed. augmentée et mise à jour, $3^{\mathrm{e}}$ tirage, París, Librairie Orientaliste Paul Geuthner, 1969.

MÉndez Rubio, Antonio, «Espacio de lo increíble. Palabras en torno a la poética de Antonio Gamoneda», en Martín Muelas Herráiz y Ángel Luis Luján Atienza (coords.), Antonio Gamoneda. Leer y entender la poesía, Cuenca, Ediciones de la Universidad de Castilla-La Mancha, 2010, 33-42.

Morier, Henri, Dictionnaire de Poétique et de Rhétorique, París, Presses Universitaires de France, $3^{\mathrm{e}}$ édition augmentée et entièrement refondue, 1981.

OrTEGA, Antonio, «La realidad plástica en Descripción de la mentira», en VV. AA., Antonio Gamoneda, Madrid, Calambur, 1993, 109-117.

PARAíso, Isabel, La métrica española en su contexto románico, Madrid, Arco/Libros, 2000, 105-106. PIERA, Carlos, Contrariedades del sujeto, Madrid, Visor, 1993.

PRIETO DE PAUlA, Ángel Luis, «Antonio Gamoneda y la construcción de un poeta», en Espacio / Espaço Escrito. Revista de Literatura en Dos Lenguas, 23-24 (Homenaje a Antonio Gamoneda y a António Ramos Rosa), 2004, 99-104.

PujANTE, David, El hijo de la persuasión. Quintiliano y el estatuto retórico, $2^{\mathrm{a}}$ ed. corregida y aumentada, Logroño, Instituto de Estudios Riojanos, 1999.

PujAnTe, David, Manual de Retórica, Madrid, Castalia, 2003. 
QUILIS, Antonio, Estructura del encabalgamiento en la métrica española (Contribución a su estudio experimental), Madrid, Consejo Superior de Investigaciones Científicas, 1964.

QuintIliano, Institutio oratoria, ed. de Michael Winterbottom, Oxford, Oxford University Press, 1970, 2 vols.

SAlinas, Pedro, Poesías completas, prólogo de Jorge Guillén, 2ª ed., Barcelona, Barral, 1975.

SCHÖPSDAU, Klaus, «Frage, rhetorische», en Gert Ueding (Hrsg.), Historisches Wörterbuch der Rhetorik, Tubinga, Max Niemayer, 1996, vol. III, 445-454.

TORRE, Esteban, Métrica española comparada, Sevilla, Universidad de Sevilla, 2000.

Varela Merino, Elena, Moíño SÁnchez, Pablo, y Jauralde Pou, Pablo, Manual de Métrica Española, Madrid, Castalia, 2005. 